\title{
Podoplanin expression in cancer-associated fibroblasts enhances tumor progression of invasive ductal carcinoma of the pancreas
}

\author{
Koji Shindo ${ }^{1,5}$, Shinichi Aishima', Kenoki Ohuchida ${ }^{2,3}$, Kenji Fujiwara ${ }^{2,5}$, Minoru Fujino', Yusuke Mizuuchi 1,5,
} Masami Hattori ${ }^{1}$, Kazuhiro Mizumoto ${ }^{2,4}$, Masao Tanaka ${ }^{2}$ and Yoshinao Oda ${ }^{1 *}$

\begin{abstract}
Background: Interactions between cancer cells and surrounding cancer-associated fibroblasts (CAFs) play an important role in cancer progression. Invasive ductal carcinoma (IDC) of the pancreas is characterized by abundant fibrous connective tissue called desmoplasia. Podoplanin (PDPN) is a lymphatic vessel marker (D2-40), and expression of PDPN by stromal CAFs has been reported to be a prognostic indicator in various types of cancer.

Methods: Expression of PDPN in pancreatic IDCs was assessed by immunohistochemical examination in 105 patients who underwent pancreatic resection. Primary CAFs were established from pancreatic cancer tissue obtained by surgery. Quantitative reverse transcription-polymerase chain reaction and flow cytometric analysis were performed to investigate PDPN expression in CAFs. We sorted CAFs according to PDPN expression, and analyzed the functional differences between PDPN+CAFs and PDPN- CAFs using indirect co-culture with pancreatic cancer cell lines. We also investigated the culture conditions to regulate PDPN expression in CAFs.

Results: PDPN expression in stromal fibroblasts was associated with lymphatic vessel invasion $(P=0.0461)$, vascular invasion ( $P=0.0101)$, tumor size $\geq 3 \mathrm{~cm}(P=0.0038)$, histological grade $(P=0.0344)$, Union for International Cancer Control classification T stage $(P=0.029)$, and shorter survival time $(P<0.0001)$. Primary CAFs showed heterogeneous PDPN expression in vitro. Moreover, migration and invasion of pancreatic cancer cell lines (PANC-1 and SUIT-2) were associated with PDPN expression in CAFs $(P<0.01)$ and expression of CD10, matrix metalloproteinase (MMP) 2 , and MMP3. In cultured CAFs, PDPN positivity changed over time under several conditions including co-culture with cancer cells, different culture media, and addition of growth factor.
\end{abstract}

Conclusions: PDPN-expressing CAFs enhance the progression of pancreatic IDC, and a high ratio of PDPNexpressing CAFs is an independent predictor of poor outcome. Understanding the regulation of the tumor microenvironment is an important step towards developing new therapeutic strategies.

Keywords: Podoplanin, Cancer-associated fibroblast, Pancreatic cancer

\section{Background}

Pancreatic cancer is one of the most lethal types of cancer. Improvements in the survival of pancreatic cancer patients have been minimal, and the 5-year survival rate remains low [1]. The poor prognosis is related to the difficulty of early diagnosis because of the absence of symptoms, and the lack of effective non-operative treatment modalities

\footnotetext{
*Correspondence: oda@surgpath.med.kyushu-u.ac.jp

'Department of Anatomic Pathology, Graduate School of Medical Sciences, Kyushu University, 3-1-1 Maidashi, Fukuoka 812-8582, Japan

Full list of author information is available at the end of the article
}

such as chemotherapy and radiotherapy [2]. Invasive pancreatic cancer tissue includes cancer, inflammatory, and fibroblastic cells, which interact with each other to create the local microenvironment. Fibroblasts recruited by the cancer tissue are called cancer-associated fibroblasts (CAFs), and play an important role in cancer progression $[3,4]$. The poor prognosis of pancreatic adenocarcinoma is partially due to the fibroblastic reaction called desmoplasia, which induces a hypovascular environment [5], inefficiency of drug delivery, and tumor-stromal interactions such as secretion of growth factors [6].

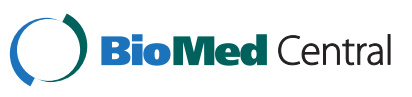


In 1998, pancreatic stellate cells (PSCs) were identified in the pancreas $[7,8]$. In the normal pancreas, PSCs are located close to the acinar cells, and retain abundant vitamin Acontaining lipid droplets in their cytoplasm as a quiescent phenotype [9]. PSCs can obtain a myofibroblast-like morphology and immunoreactivity for alpha-smooth muscle actin $(\alpha$-SMA) by inflammatory stimulation or signals from cancer cells, such as interleukin (IL)-1, IL-6, tumor necrosis factor-alpha, platelet-derived growth factor, transforming growth factor (TGF)- $\beta 1$, and activin A [10]. Activated PSCs produce abundant extracellular matrix (ECM), leading to cancer progression $[9,11]$. In addition, activated PSCs harvested by the outgrowth method have characteristics similar to those of CAFs. Recently, CAFs have gained attention as a potential therapeutic target $[12,13]$.

Podoplanin (PDPN) is a $38-44 \mathrm{kDa} O$-glycosylated transmembrane glycoprotein that is selectively expressed by lymphatic endothelial cells [14]. PDPN is also expressed by normal kidney podocytes [15], alveolar type I cells [16], basal epidermal keratinocytes [17], and mesothelial cells $[18,19]$. Several types of cancer may also express PDPN, such as squamous cell carcinomas [20,21], soft tissue tumors [22], and brain tumors [23]. PDPN-expressing cancer cells have enhanced malignant potential due to enhancement of platelet aggregation, which promotes metastasis [24,25], alteration of cell morphology and motility $[26,27]$, and epithelial-mesenchymal transition [28]. Stromal fibroblasts surrounding cancer cells may also express PDPN [29-36]. The presence of PDPN-expressing fibroblasts has been reported to be a prognostic indicator in several types of cancer, but outcomes vary according to the type of cancer [30,33-36]. Understanding the molecular mechanisms of PDPN expression is important for the development of new therapeutic strategies for the treatment of malignant tumors with PDPN-positive fibroblasts.

In this study, we examined PDPN expression in invasive ductal carcinoma (IDC) of the human pancreas using immunohistochemical methods, and investigated the functional roles of PDPN-expressing CAFs established from pancreatic IDCs by cell sorting. CD10+ PSCs were previously found to enhance the progression of pancreatic cancer in a similar manner to CAFs, depending on matrix metalloproteinase (MMP) 3 secretion [13]. In this study, we found that PDPN+ and PDPN-CAFs had functional differences associated with their expression of CD10, MMP3, and MMP2. We also found that PDPN expression in CAFs was affected by both cancer cell-stromal interactions and environmental conditions.

\section{Results}

Correlations between PDPN expression in fibroblasts and clinicopathologic characteristics

Numerous fibroblasts were observed in the area of cancerous invasion (Figure 1A-a), and PDPN+ fibroblasts were observed close to the tumor cells (Figure 1A-b). In normal pancreatic tissue including the main pancreatic duct, PDPN+ fibroblasts were rarely observed (Figure 1A-c). PDPN+fibroblasts ( $\geq 30 \%)$ were observed in $70.5 \%(74 / 105)$ of pancreatic IDCs, but no PDPN+ cancer cells were observed. Patients in the PDPN+ group had more frequent lymphatic invasion $(P=0.0461)$, vascular invasion $(P=0.0101)$, tumor size $\geq 3 \mathrm{~cm}(P=$ $0.0038)$, G3 grade tumor $(P=0.0344)$, and Union for International Cancer Control (UICC) grade pT3 or higher $(P=$ 0.029 ) than patients in the PDPN- group (Table 1). These results suggest that $\mathrm{PDPN}+$ stromal fibroblasts are associated with tumor progression and the invasiveness of cancer cells.

\section{Stromal PDPN expression is independently associated with shorter survival time}

PDPN+ stromal fibroblasts were associated with shorter patient survival and disease-free survival times (Figure 1B, $\mathrm{C})$. The median survival times for PDPN+ and PDPNcases were 14 and 33 months, respectively. Multivariate survival analysis based on the Cox proportional hazards model including all parameters found to be significant on univariate analyses (data not shown), including PDPN positivity, lymphatic invasion, vascular invasion, tumor size $\geq 3 \mathrm{~cm}, \mathrm{G} 3$ tumor, UICC grade $\mathrm{pT} 3 / 4$, UICC grade pN1, and stage III/IV (Table 2) [37], found that PDPN positivity (relative risk $2.598, P=0.0030$ ) and UICC N1 category $(P=0.0302)$ were independent markers of poor prognosis (Table 2) [37].

\section{CAFs have heterogeneous PDPN expression}

We investigated PDPN mRNA expression in 22 CAF cultures that were numbered from 1 to 22 by quantitative reverse transcription-polymerase chain reaction (qRT-PCR) (Figure 2A). Primary CAF cultures expressed various levels of PDPN mRNA, and CAF1 cells showed significantly high expression. The pancreatic cancer cell line PANC-1 did not express PDPN mRNA. Flow cytometric analysis showed that cultured CAFs exhibited various positivity rates $(0.4-94 \%)$ for PDPN in accordance with the results of qRT-PCR (Figure 2B). We confirmed that PDPN expression had not been affected by proteolysis during trypsin/EDTA treatment using flow cytometric analysis (Additional file 1: Figure S1A), and immunocytochemical staining of CAFs (Additional file 1: Figure S1B). All the primary cultured CAFs (CAF1, CAF2, CAF3, and CAF4) were positive for fibroblast activation protein-alpha (FAP) in most cells (Additional file 1: Figure $\mathrm{S} 1 \mathrm{C})$. Immunofluorescence staining showed CAFs as spindle-shaped and stellate-like cells, and almost all cells were stained for $\alpha$-SMA and partly stained for PDPN (Figure 2C). CAFs are therefore heterogeneous in terms of PDPN expression. 
A

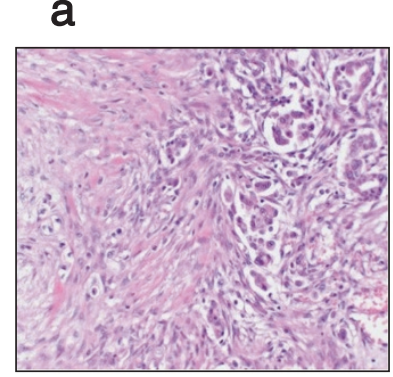

IDC (HE) $\times 200$ b

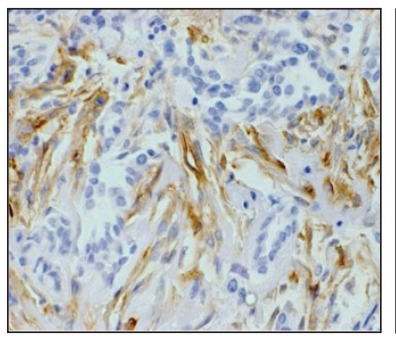

IDC (PDPN) x400

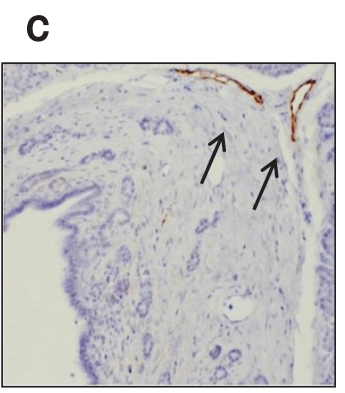

Normal MPD x200

B

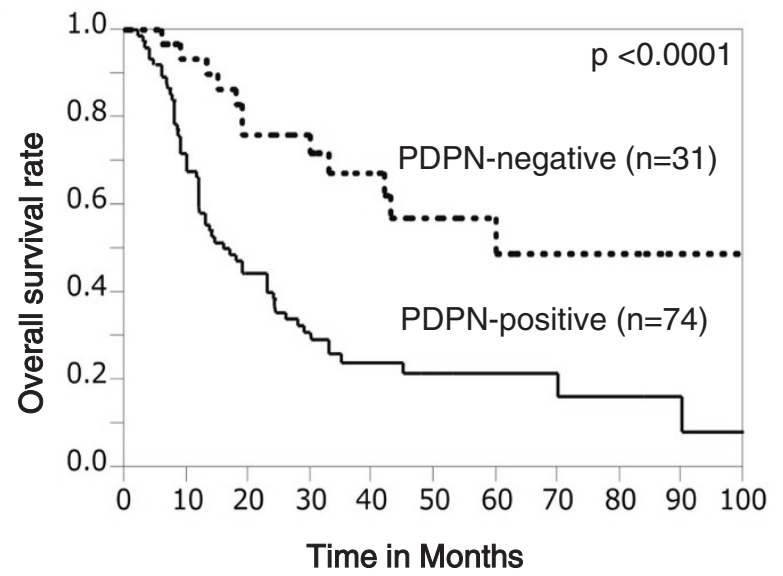

C

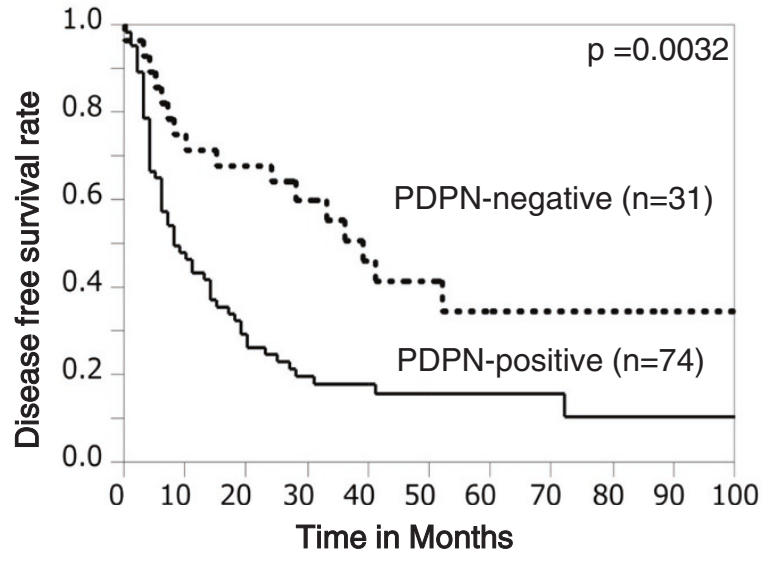

Figure 1 Immunohistochemical staining for PDPN in IDC of the pancreas. (A-a) Pancreatic IDCs consisted of cancer cells and stromal cells such as CAFs. (A-b) CAFs around the cancer cells were positive for PDPN. (A-c) In the normal main pancreatic duct, stromal cells were rarely positive for PDPN. The arrow indicates lymphatic vessels as a positive control. (B, C) Stromal PDPN expression was associated with a worse overall survival rate $\mathbf{( B )}$ and disease-free survival rate $\mathbf{( C )}$ by Kaplan-Meier survival analysis.

CAFs enhance the invasive potential of pancreatic cancer cells To investigate the effects of CAFs on the invasiveness of pancreatic cancer cells, we used a transwell co-culture system as described previously [13]. Fujita et al. [38] reported that the proliferation of pancreatic cancer cells was not enhanced by the conditions of an indirect co-culture system. We confirmed those findings, and assumed that the increase in invasiveness of cancer cells was not accelerated by the proliferation of cancer cells. PANC-1, SUIT-2, and
KP2 pancreatic cancer cells were co-cultured with CAF1 (high PDPN-expressing cells) or CAF2 (PDPN- cells) in the transwell system. Pancreatic cancer cells strongly migrated (Figure 3A,B) and invaded (Figure 3C,D) when cocultured with CAF1 cells. On the other hand, CAF2 cells had a lesser effect on migration and invasion of cocultured cancer cells. Therefore, we hypothesized that the differences in the invasive potential of cancer cells were due to PDPN expression in CAFs. 
Table 1 Relationships between PDPN expression and clinicopathologic factors

\begin{tabular}{|c|c|c|c|c|}
\hline \multicolumn{2}{|c|}{ Characteristics } & \multirow{2}{*}{$\frac{\text { PDPN negative, } \mathbf{n}=\mathbf{3 1}(\mathbf{2 9 . 5 \% )}}{11(35.5)}$} & \multirow{2}{*}{$\begin{array}{c}\text { PDPN positive, } \mathbf{n}=\mathbf{7 4}(\mathbf{7 0 . 5 \% )} \\
13(17.6)\end{array}$} & \multirow{2}{*}{$\frac{\text { p Value }}{0.0461^{*}}$} \\
\hline Lymphatic invasion & No & & & \\
\hline & Yes & $20(64.5)$ & $61(82.4)$ & \\
\hline \multirow[t]{2}{*}{ Vascular invasion } & No & $17(54.8)$ & $21(28.4)$ & $0.0101^{*}$ \\
\hline & Yes & $14(45.2)$ & $53(71.6)$ & \\
\hline \multirow[t]{2}{*}{ Tumor size } & $<3 \mathrm{~cm}$ & $23(74.2)$ & $32(43.2)$ & $0.0038^{*}$ \\
\hline & $\geq 3 \mathrm{~cm}$ & $8(25.8)$ & $42(56.8)$ & \\
\hline \multirow[t]{2}{*}{ Histologic Grade } & G1/G2 & $20(64.5)$ & $31(41.9)$ & $0.0344^{*}$ \\
\hline & G3 & $11(35.5)$ & $43(58.1)$ & \\
\hline UICC & $\mathrm{pT} 1 / \mathrm{pT} 2$ & $8(25.8)$ & $7(9.5)$ & $0.0290^{*}$ \\
\hline T category & $\mathrm{pT} / \mathrm{pT} 4$ & $23(74.2)$ & $67(90.5)$ & \\
\hline UICC & $\mathrm{pNO}$ & $14(45.2)$ & $20(27.0)$ & 0.0701 \\
\hline N category & $\mathrm{pN} 1$ & $17(54.8)$ & $54(73.0)$ & \\
\hline \multirow[t]{3}{*}{ UICC stage } & । & $7(22.6)$ & $5(6.8)$ & 0.0642 \\
\hline & $\|$ & $23(74.2)$ & $65(87.8)$ & \\
\hline & III/IV & $1(3.2)$ & $4(5.4)$ & \\
\hline
\end{tabular}

Significant differences between samples are indicated as ${ }^{*} P<0.05$. UICC, Union for International Cancer Control.

PDPN+ CAFs enhance the invasive potential of pancreatic cancer cells more effectively than PDPN-CAFs

To clarify the differences in enhancement of invasive potential between PDPN+ and PDPN- CAFs, we sorted CAFs by magnetic-activated cell sorting (Additional file 2: Figure S2A). The level of PDPN mRNA expression in PDPN+ and PDPN-CAFs derived from CAF3 and CAF4 cells was consistent with the level of PDPN expression found by flow cytometry (Additional file 2: Figure S2B). We investigated the effects of these two populations on the invasiveness of PANC-1 and SUIT-2 cells using migration and invasion assays in a co-culture system. PDPN + CAF3 and CAF4 cells enhanced the migration (Figure 4A) and invasion (Figure 4B) of PANC-1 and SUIT-2 cells more strongly than PDPN-CAFs $(P<0.01)$.
Knockdown of PDPN in CAFs has no effect on the enhancement of invasiveness of pancreatic cancer cells PDPN is a known transmembrane protein, but not a secreted protein. Despite no detection of PDPN in culture supernatants of CAFs (data not shown), PDPN+ CAFs had a promoting effect on cancer cell invasion in the indirect co-culture system. We compared CAF1 cells with and without PDPN knockdown by small interfering RNA (siRNA) (Additional file 3: Figure $\mathrm{S} 3 \mathrm{~A}, \mathrm{~B})$ to clarify the functional role of PDPN. There were no changes in migration (Additional file 3: Figure S3C) or invasion (Additional file 3: Figure S3D) of PANC-1 and SUIT-2 cells when they were co-cultured with PDPN-knockdown CAF1 cells. These data suggest that PDPN itself has no effect on the invasion and migration of pancreatic cancer cells, whereas PDPN + CAFs promote these features.

Table 2 Multivariate survival analysis (Cox regression model) of conventional prognostic factors and PDPN expression

\begin{tabular}{lccc}
\hline & Relative Risk & 95\% Confidence interval & p Value \\
\hline PDPN positivity & 2.598 & $1.363-5.390$ & $0.003^{*}$ \\
Lymphatic invasion & 1.483 & $0.643-3.892$ & 0.3694 \\
Vascular invasion & 1.389 & $0.736-2.720$ & 0.3149 \\
Tumor size & 1.311 & $0.745-2.322$ & 0.3474 \\
Histological Grade & 1.151 & $0.676-1.988$ & 0.6061 \\
UICC T category & 0.245 & $0.067-1.580$ & 0.1198 \\
UICC N category & 2.07 & $1.069-4.282$ & $0.0302^{*}$ \\
UICC Stage & & & 0.1550 \\
\hline
\end{tabular}

NOTE. The relative risk of the UICC stage is not shown because it is comprised of two parameters. Significant differences are indicated as $* P<0.05$. UICC, Union for International Cancer Control, $7^{\text {th }}$ edition. 
A

PDPN/GAPDH

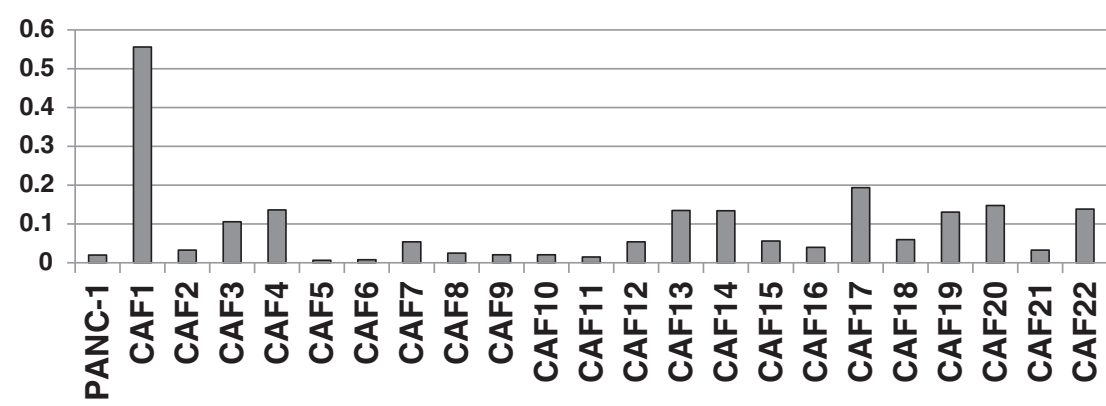

B
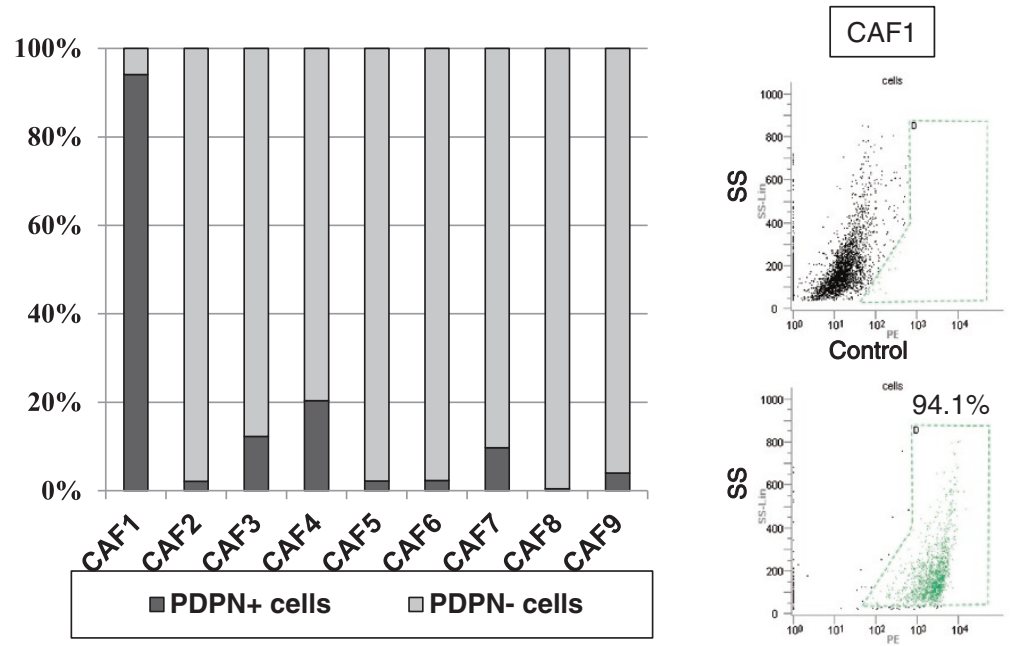

PE-conjugated PDPN

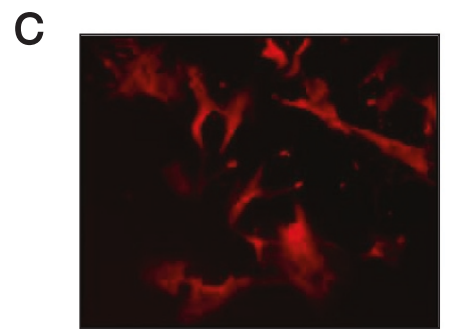

$\alpha-S M A$

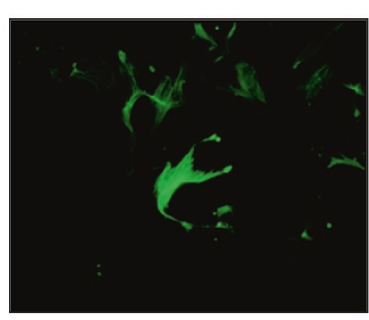

PDPN

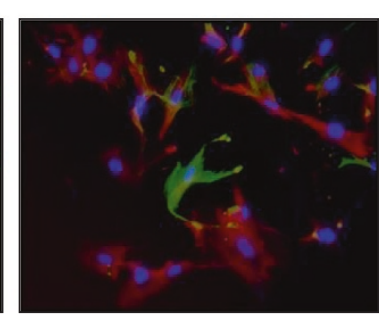

DAPI Merge

Figure 2 PDPN expression was heterogeneous in CAFs. (A) qRT-PCR showed variable PDPN expression in CAFs. The pancreatic cancer cell line PANC-1 expressed less PDPN mRNA than CAFs. (B) Flow cytometry showed 0.4-94\% positivity rates for PDPN expression. Representative flow cytometry data for PDPN expression in CAF1 cells are shown (right). (C) Immunofluorescence staining for PDPN (green) and a-SMA (red) in CAF4. CAFs had spindle-shaped or stellate-like morphology and expressed a-SMA and PDPN. Original magnification × 100 .

Differences in cancer cell invasion-related gene expression between PDPN+ and PDPN- CAFs

To detect differences between PDPN+ and PDPN- CAFs, we analyzed the mRNA and protein from various CAFs (CAF1, CAF2, and CAF3 and CAF4 cells sorted by PDPN expression). CAF1 cells and PDPN+CAFs expressed more CD10, MMP3, and MMP2 than CAF2 cells and PDPNCAFs (Figure 5A). CD10 is a cell surface metalloproteinase, and MMPs promote cancer cell invasion by degrading structural ECM proteins $[39,40]$. In particular, CD10+ PSCs have been reported to promote cancer-stromal interactions by secreting high levels of MMP3 [13]. The level of PDPN protein expression in CAFs was correlated with that of CD10 expression (Figure 5B), which was also the trend observed in qRT-PCR analysis. These findings suggest that PDPN+CAFs in pancreatic cancer play a pivotal role in increasing the invasive potential of cancer cells.

The number of PDPN+CAFs is increased through cancer-stromal interactions

We investigated the effects of cancer cells on PDPN expression in CAFs using an indirect co-culture system. When 

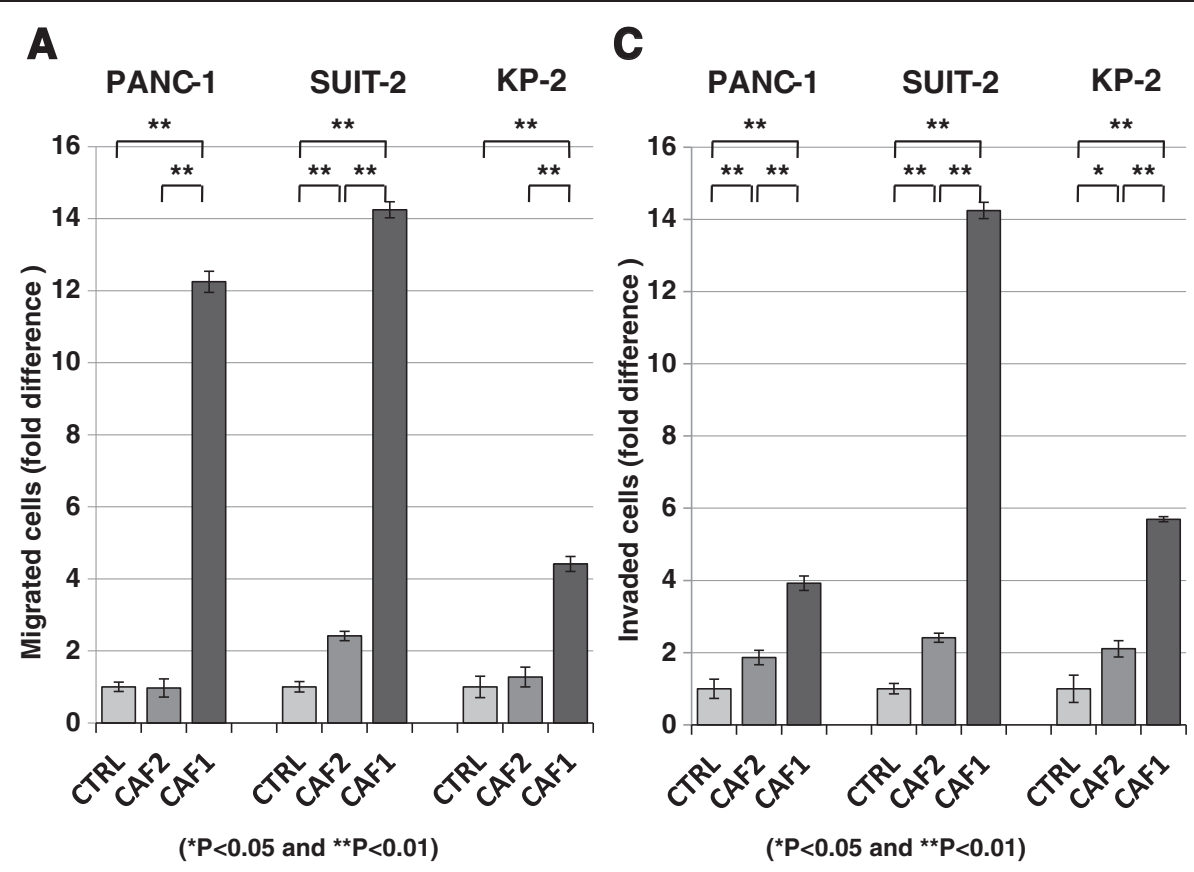

\section{B}

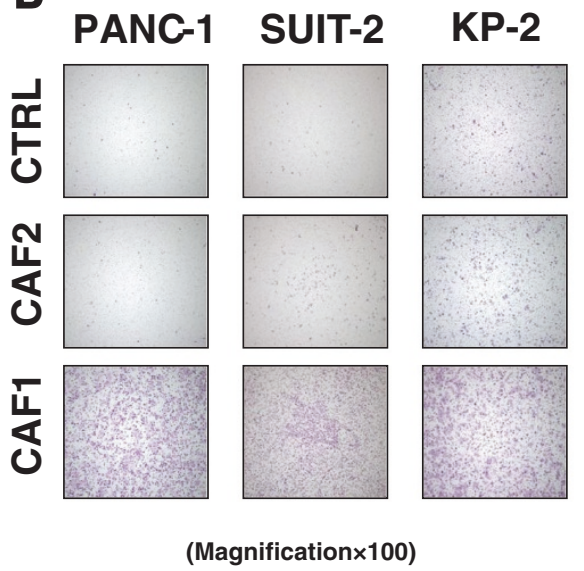

D

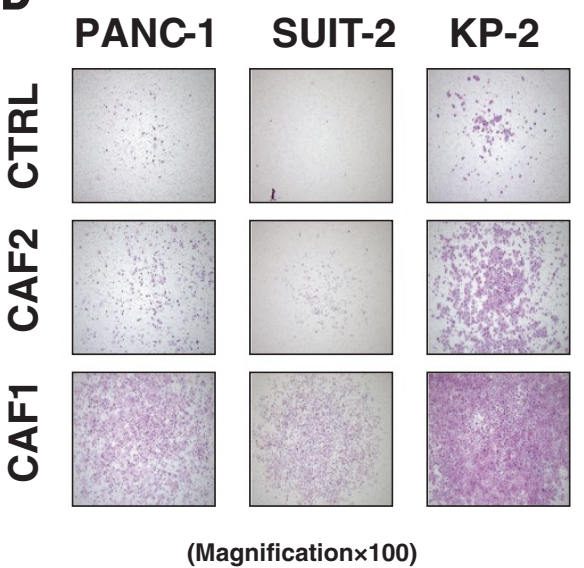

Figure 3 Effects of CAFs (CAF1 and CAF2 cells) on the invasive potential of pancreatic cancer cells. CAF1 (high PDPN-expressing cells) promoted the migration (A, B) and invasion (C, D) of PANC-1, SUIT-2, and KP-2 cells compared with CAF2 (PDPN- cells). Significant differences between sample means are indicated as ${ }^{*} P<0.05,{ }^{*} P<0.01$. (B, D) Representative photomicrographs of migrating (B) and invading (D) cancer cells co-cultured with CAFs (hematoxylin and eosin staining; original magnification $\times 40$ ).

co-cultured with a variety of pancreatic cancer cell lines in Dulbecco's modified Eagle's medium (DMEM) / 2\% fetal bovine serum (FBS), the populations of PDPN-expressing CAFs increased in a time-dependent manner, especially CAF4 on day 5, compared with CAF monocultures (Figure 6). The numbers of CAF4 were almost same on days 3 and 5, indicating a possible change in the expression pattern from PDPN- to PDPN+.

\section{The number of PDPN+ CAFs is affected by the culture} conditions

In co-cultures, all cancer cell lines significantly increased PDPN expression in CAF4 cells on day 5. Therefore, we hypothesized that PDPN expression was not only affected by specific signals, but also by environmental conditions. Wicki et al. [27] reported that PDPN expression in the breast cancer cell line MCF7 is up-regulated by stimulating growth factors such as TGF- $\beta$, fibroblast growth factor (FGF)-2, and epidermal growth factor (EGF). However, when we added the growth factors TGF- $\beta 1$, FGF-2, insulin-like growth factor (IGF)-1, and EGF to serum-free DMEM, PDPN+ populations among CAF3 and CAF4 cells mostly decreased in a time-dependent manner (Figure 7A). In CAF4 cell cultures, however, addition of FGF-2 or IGF1 had a lesser effect on PDPN+ populations (Figure 7A). Next, we investigated the effects of added FBS on PDPN+ 


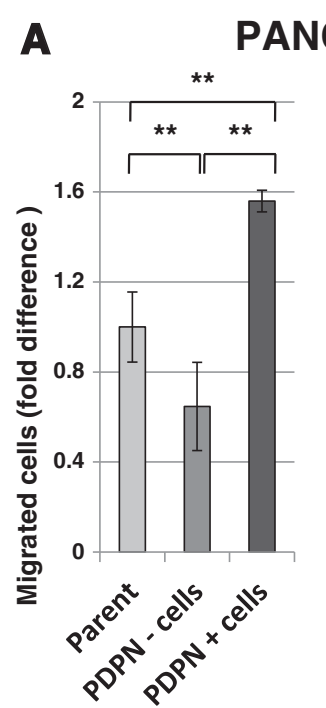

CAF 3

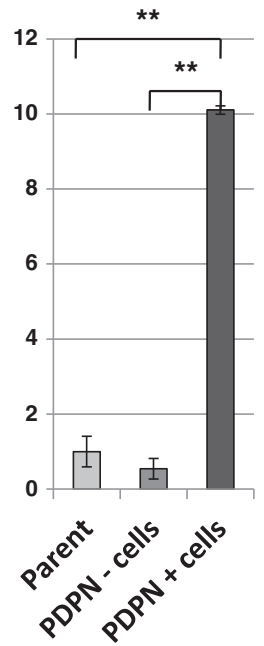

CAF 4

$\left({ }^{\star \star} P<0.01\right)$

B

PANC-1

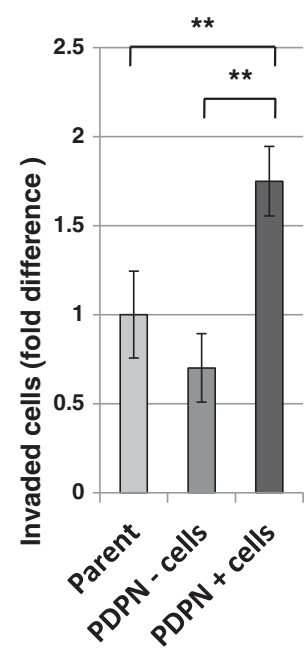

CAF 3
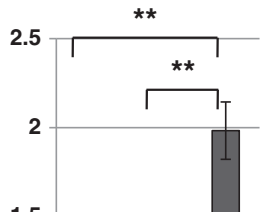

1.5

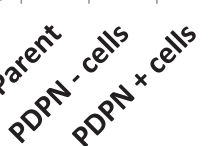

CAF 4

$\left({ }^{\star \star} P<0.01\right)$

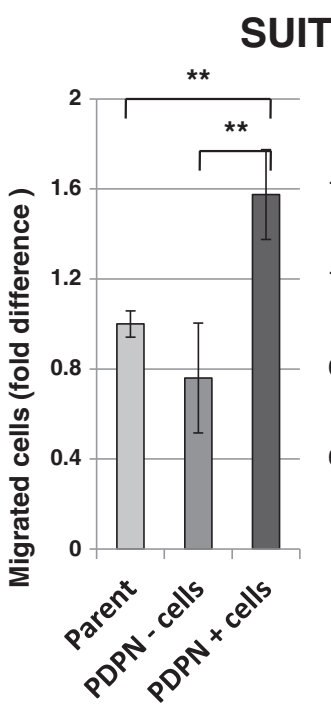

CAF 3

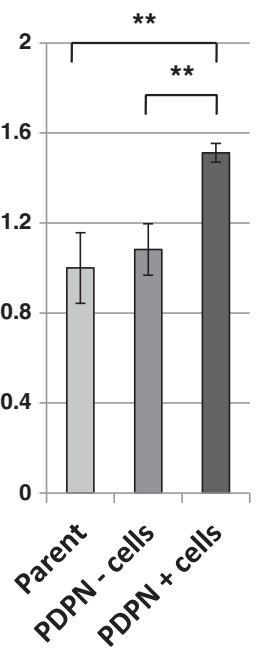

CAF 4 ( $\left.{ }^{\star \star} P<0.01\right)$

\section{SUIT-2}

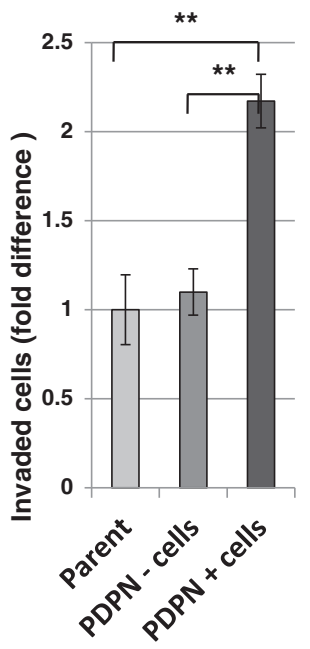

CAF 3

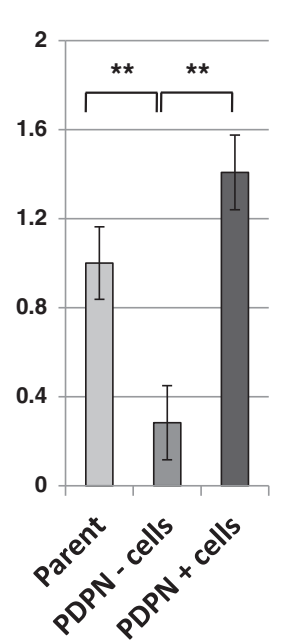

CAF 4

$\left({ }^{\star *} \mathrm{P}<0.01\right)$

Figure 4 Effects of sorted CAFs on the invasiveness of pancreatic cancer cells. PDPN+CAFs promoted the migration (A) and invasion (B) of PANC-1 and SUIT-2 cells compared with PDPN- CAFs. The $P$ values for the migration assays were: $P=0.0001$ (PANC-1 with CAF3), $P=0.0003$ (PANC-1 with CAF4), $P=0.0034$ (SUIT-2 with CAF3), and $P=0.0058$ (SUIT-2 with CAF4). The $P$ values for the invasion assays were: $P=0.0013$ (PANC-1 with CAF3), $P=0.0022$ (PANC-1 with CAF4), $P=0.0065$ (SUIT-2 with CAF3), and $P=0.0013$ (SUIT-2 with CAF4). Significant differences between sample means are indicated as ${ }^{* *} P<0.01$.

populations. We compared PDPN+ populations among CAF3 and CAF4 cells when cultured in DMEM with or without several concentrations of FBS. Control cells were cultured in DMEM with 10\% FBS, and the medium was changed every day. Addition of FBS attenuated the increasing rate of $\mathrm{PDPN}+$ populations, depending on the FBS concentration. However, PDPN+ cells among CAFs increased in a time-dependent manner despite ad- ministration of FBS (Figure 7B). In addition, the populations of PDPN+CAFs cultured in serum-free DMEM increased more significantly than those cultured in glucoseand serum-free DMEM (Figure 7C). These findings suggest that PDPN+CAFs are affected by culture conditions, and PDPN+ populations increase in a time-dependent manner when cultured in DMEM containing glucose and decrease in high concentrations of FBS and growth factors. 


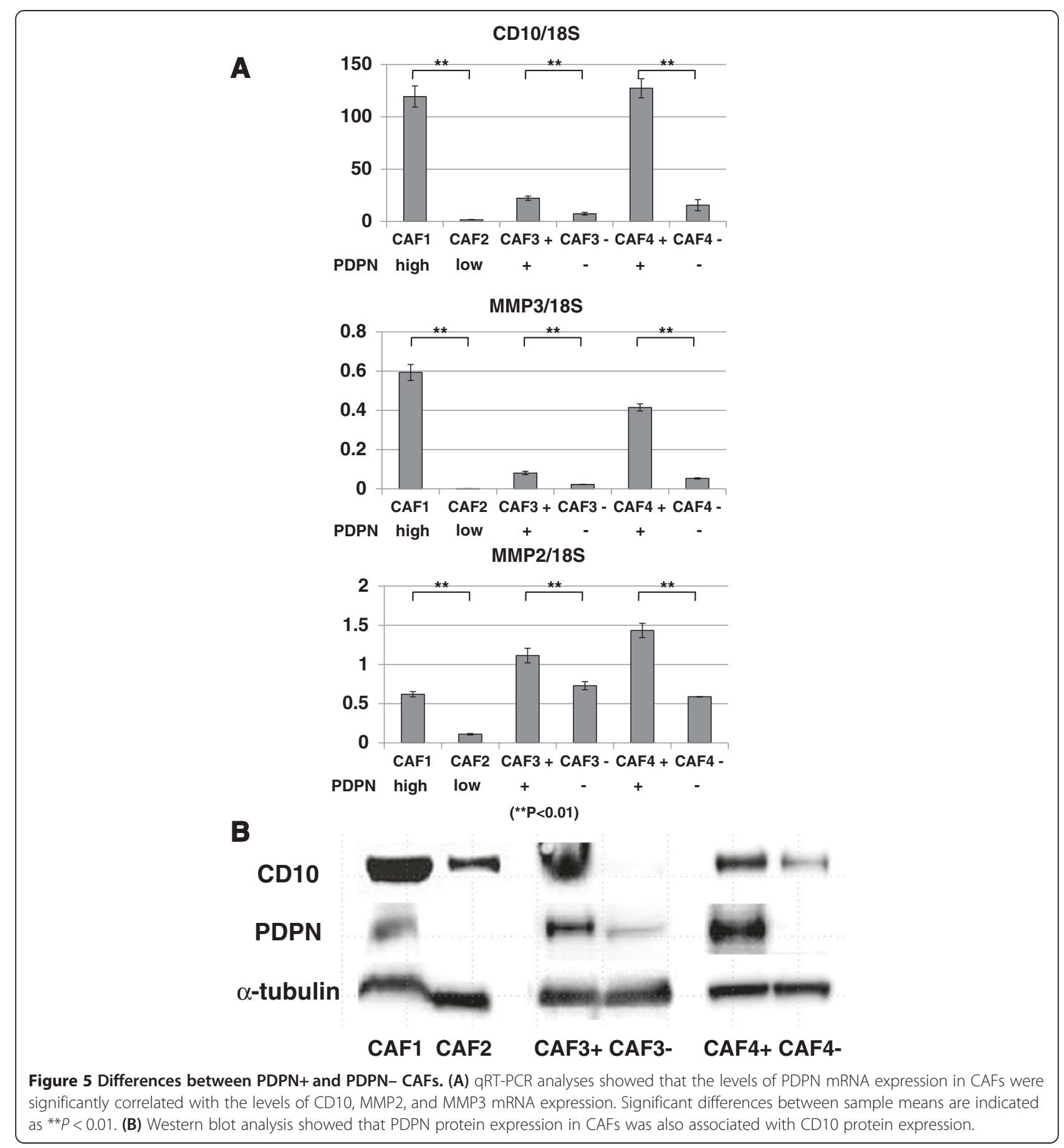

\section{Discussion}

In the present study, PDPN-expressing CAFs were found in IDC tissue of the pancreas. We revealed the significance of these cells in terms of cancer cell invasion, in correlation with shorter patient survival and several biological factors, namely lymphatic and vascular invasion, larger tumor size, histological grade, and UICC T grade [37]. Kitano et al. [33] assessed PDPN-expressing stromal spindle cells in multiple cancer tissues including pancreatic cancer using tissue microarrays. They found a $73 \%(16 / 22)$ positivity rate for PDPN expression in pancreatic cancer. In this study, positive PDPN expression was found in $70.5 \%(74 / 105)$ of cases when we defined the cutoff value in stromal fibroblasts as $30 \%$. We therefore consider this to be an appropriate cutoff value.

In recent clinicopathological studies of other cancer types, PDPN expression in the cancerous stroma was reported to be a prognostic indicator, but the effects on 


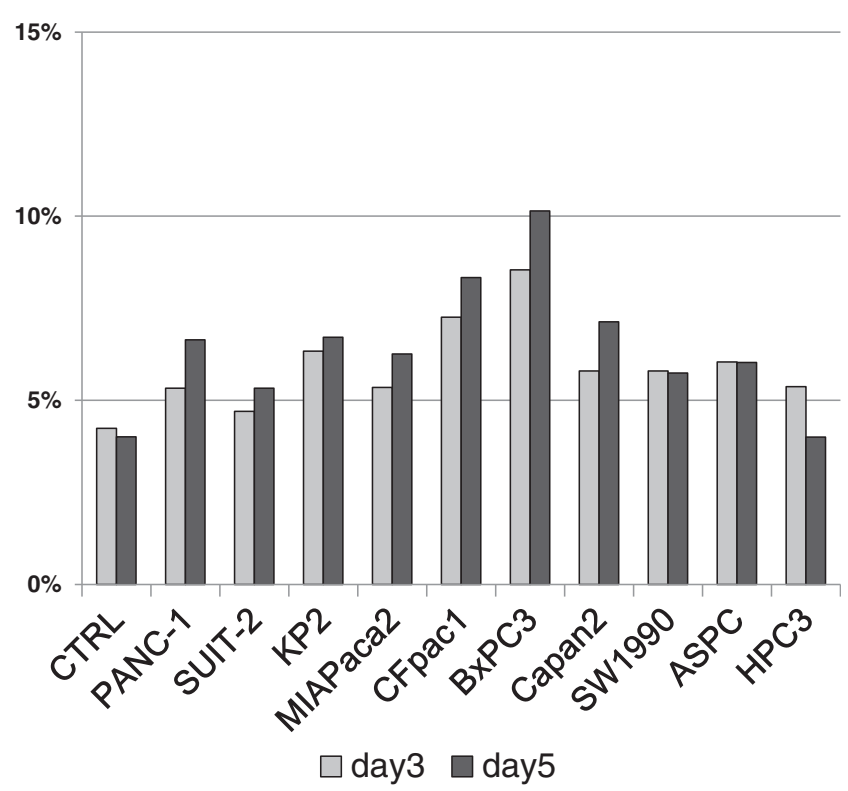

CAF3

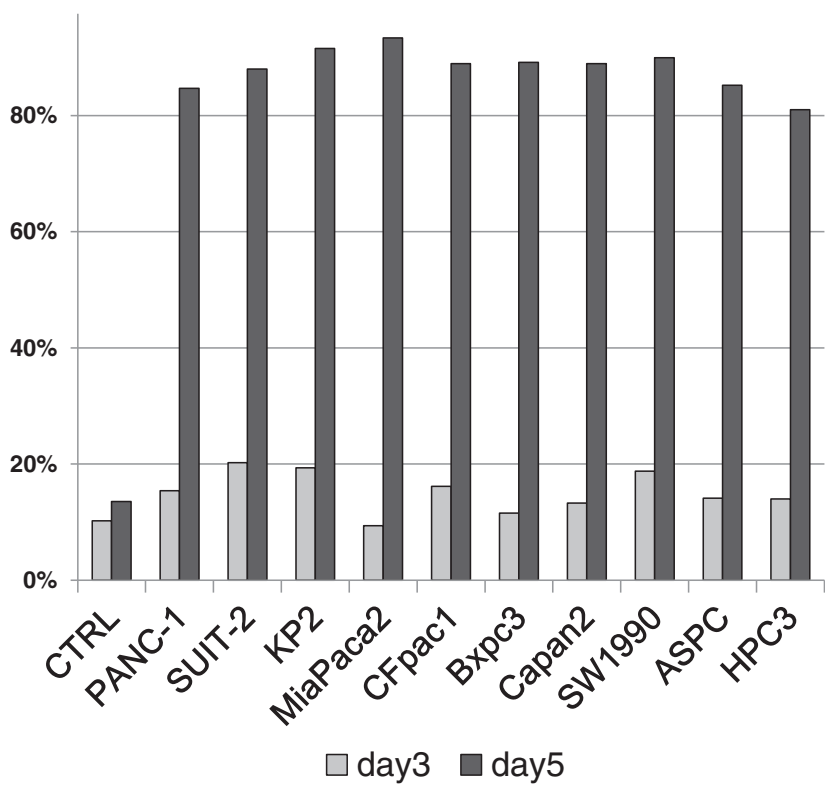

Figure 6 Percentage of PDPN+ cells among CAFs indirectly co-cultured with pancreatic cancer cells. CAFs were cO-cultured with the indicated pancreatic cancer cell lines for several days, and then the percentage of PDPN+CAFs was assessed by flow cytometry.

prognosis varied depending on the cancer type. High PDPN expression in fibroblasts is significantly correlated with a poor prognosis in IDC of the breast [34], lung adenocarcinoma [31-33], and ovarian carcinoma [36]. Conversely, PDPN-expressing fibroblasts indicate a favorable outcome in colorectal carcinoma [35] and uterine cervical carcinoma [30].

Some of the biological functions of PDPN in cancer cells have been partially elucidated in several studies, but the biological characteristics of PDPN-expressing stromal fibroblasts are largely unknown. Yamanashi et al. [35] showed increased invasion of colorectal cancer cells when they were co-cultured with fibroblasts with PDPN knockdown by siRNA. However, the interactions between the cells were not described, and the fibroblasts were from a colonic fibroblast cell line (CCD112CoN from 22 weeks of gestation) rather than from cancer tissue.

Knockdown of PDPN by siRNA had no effect on the enhancement of cancer cell invasiveness in our study. However, Hoshino et al. [31] reported that PDPNexpressing CAFs in lung adenocarcinoma promote tumor formation both in vivo and in vitro using transfection by short hairpin RNA against PDPN expression. 


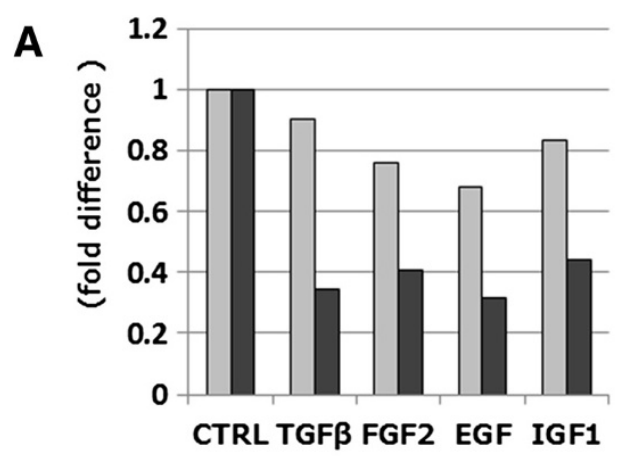

CAF3 $\square$ day2 $\square$ day4

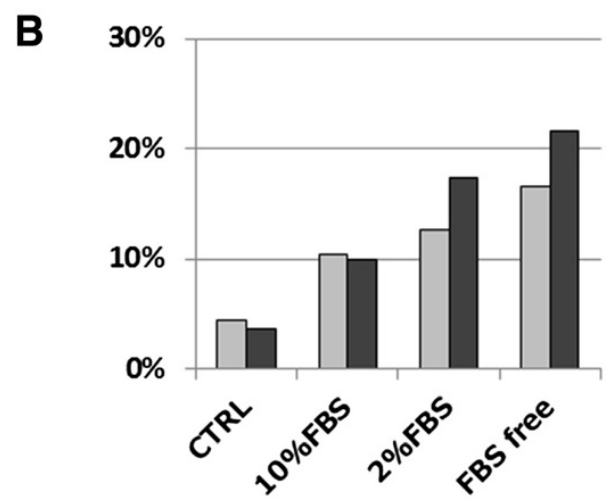

CAF3 口day3 घday5

C

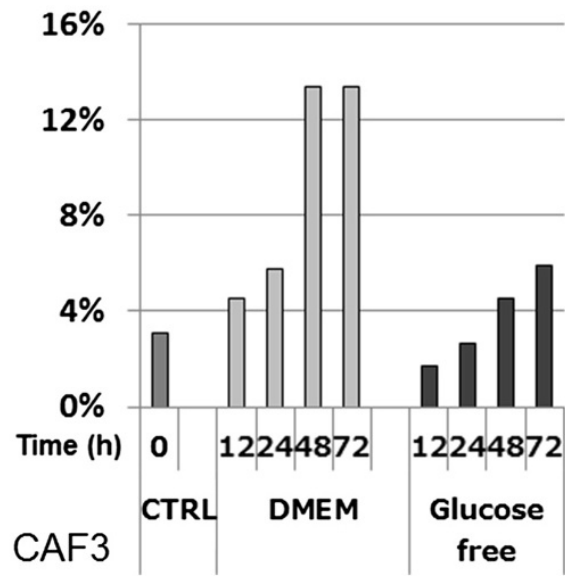

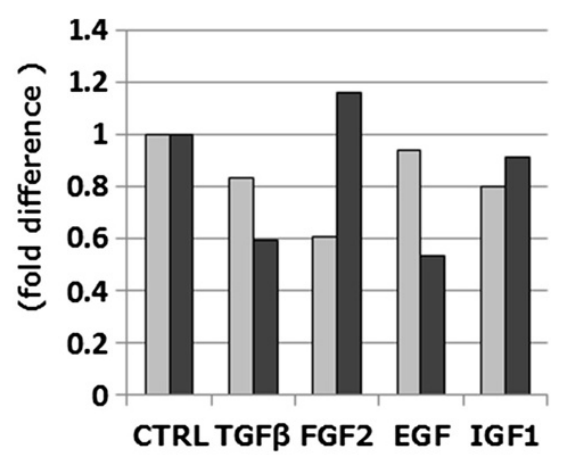

CAF4 $\square$ day2 $\square$ day4

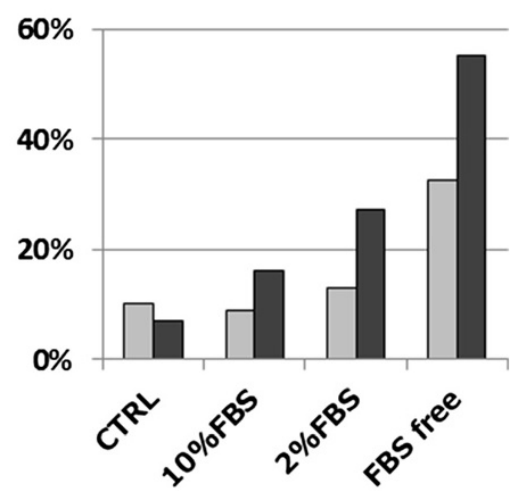

CAF4 $\square$ day3 $\square$ day5

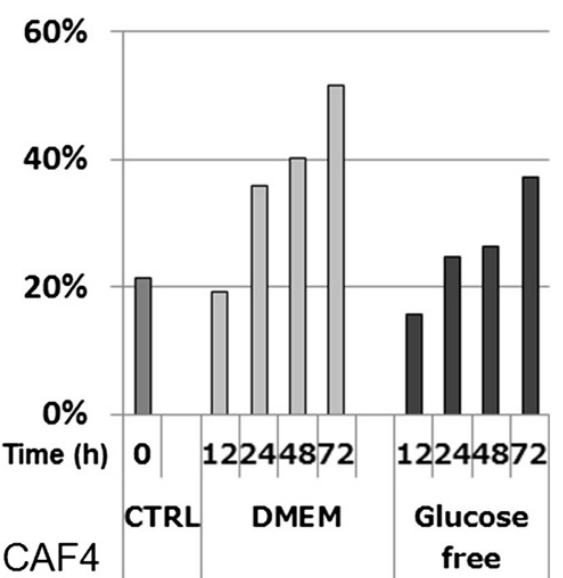

Figure 7 Populations of PDPN+ cells among CAFs affected by environmental conditions. (A) The percentage of PDPN+ cells among CAFs changed in a time-dependent manner by culturing with DMEM-containing growth factors. (B) Populations of PDPN+ cells among CAFs changed by the addition of FBS in concentration- and time-dependent manners. The control (CTRL) condition consisted of DMEM containing $10 \%$ FBS and medium changes every day. (C) Populations of PDPN+ cells in cultures of serum-free DMEM increased more rapidly than those in cultures of glucose- and serum-free DMEM.

According to transfection studies in human MCF7 breast cancer cells, PDPN expression results in morphological changes, induction of migratory phenotypes with a significant decrease in cellular stress fibers, and an increase in filopodia-like protrusions [27]. In our study, PDPN knockdown CAFs did not show any notable changes in morphology compared with parental CAFs (data not shown). The differences in alteration of morphology might therefore be dependent on the cell type.

PSCs were originally identified as the source of fibrosis in chronic pancreatitis [7], and were assumed to be the source of desmoplasia in pancreatic cancers. We used PSCs obtained by the outgrowth method as CAFs, 
because activated PSCs have a myofibroblast-like shape and are positive for $\alpha$-SMA and vimentin, which is similar to CAFs. It was therefore very difficult to differentiate between PSCs and CAFs on immunohistochemical staining. The characteristic differences in CAFs originating from different tumors might be explained by them originating from diverse sources, such as resident local fibroblasts, bone marrow-derived progenitor cells, and transdifferentiation of epithelial/endothelial cells by epigenetic transition [41]. Vascular adventitial fibroblasts in lung adenocarcinoma have biological functions similar to those of CAFs, and PDPN is highly expressed in vascular adventitial fibroblasts in association with cancer progression [31]. The differences in biological function of PDPN+CAFs in diverse cancers might therefore be based on the characteristics of their origins.

With the increasing understanding of the roles of CAFs, various discussions exist regarding their origins, specific markers, and characteristics [42]. Erez et al. [43] reported the differences in proinflammatory genes as signature genes between normal fibroblasts and CAFs in pancreatic ductal adenocarcinoma especially in mice. Cyclooxygenase 2, Chemokine (C-X-C motif) ligand (CXCL) 1, CXCL2, cysteine-rich 61 , IL-1 $\beta$, IL-6, and osteopontin differed in their mRNA expression. When we investigated these signature genes in our CAFs (CAF1, CAF2, CAF3+/-, and

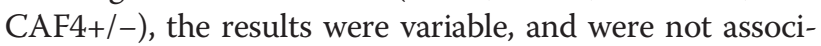
ated with PDPN expression (data not shown). Several markers for CAFs have been identified, including $\alpha$-SMA and FAP. In previous studies, FAP-expressing fibroblasts were reported to enhance the cancer cell invasion by producing ECM [44], and have essential functions in maintaining muscle mass and hematopoiesis [45]. Most of the primary cultured CAFs in our study were $\alpha$-SMA positive [13] and FAP positive.

The interactions among cancer cells, stromal cells such as CAFs, and inflammatory cells create the tumor microenvironment, and remodel the surrounding ECM when cancer cells become invasive. Growth factors also have important effects on adjacent cells in an autocrine and paracrine fashion [11]. In addition, MMPs are known to play important roles in cell migration and degradation of the surrounding ECM [40].

In our laboratory, Fujita et al. reported that conditioned medium from PSCs established by the outgrowth method enhanced colony formation of SUIT-2 cells in the same way as co-culture. However, colony formation of MIAPaCa-2 cells was not enhanced by the conditioned medium [46]. Ikenaga et al. revealed that CD10expressing PSCs promoted the invasiveness of cancer cells by secreting MMP3, which was confirmed in the supernatant [13]. Hwang et al. also reported that conditioned medium from PSCs stimulated cancer cell proliferation, invasion, and colony formation [3]. The effect of
PDPN expression on the conditioned medium of CAFs in this study was unclear. However it is likely that this medium would have similar effects on the invasiveness of cancer cells as co-culture with CAFs, given the differences in CD10 expression and MMP secretion between PDPN-positive and -negative CAFs.

FBS contains high concentrations of embryonic growth-promoting factors, and is widely used as a growth supplement to enhance cell survival and proliferation, although the composition of FBS is not fully understood. We found that PDPN+CAFs were important modulators of MMP expression. In addition, the reduction in the numbers of PDPN+CAFs after addition of growth factors or high concentrations of FBS suggests the possibility of negative feedback by growth factors.

\section{Conclusions}

Although the molecular mechanisms of PDPN expression in CAFs are not clear, and CAFs have functional heterogeneity, we found that PDPN+CAFs play an important role in cancer cell invasion in association with the expression of CD10, MMP2, and MMP3. It is important to develop new therapeutic strategies to target the supportive microenvironment provided by cancerstromal interactions in pancreatic cancer.

\section{Methods}

\section{Patients and pancreatic tissue}

Pancreatic cancer tissue was obtained from 105 patients who underwent pancreatic resection for IDC of the pancreas at our institution from 1995 to 2011. The clinicopathologic characteristics of the patients are shown in Additional file 4: Table S1. The patients included 70 men and 35 women with a median age of 65 years (range: 4386 years). Survival was measured from the time of pancreatic resection until death or censor. The follow-up duration ranged from 1 to 137 months, and the median overall survival time was 19 months. Seventy-three patients died during follow-up. The histological diagnosis of the specimens was confirmed according to the criteria of the updated World Health Organization classification [47]. The tumor stage was assessed according to the UICC classification, $7^{\text {th }}$ edition [37]. Lymphatic and vascular invasion were detected by hematoxylin and eosin staining. When necessary, we performed D2-40 (PDPN) staining to determine lymphatic invasion and Elastica van Gieson staining to determine vascular invasion. Patients were divided into groups for statistical analysis as shown in Table 1. We also obtained 20 normal pancreatic tissue samples from intact pancreatic specimens that were resected for solid-pseudopapillary neoplasm or neuroendocrine tumor, as control tissue. This study was approved by the Ethics Committee of Kyushu University (approval number 25-23, 24-222) and was conducted according to 
the Ethical Guidelines for Human Genome/Gene Research enacted by the Japanese Government and the Helsinki Declaration.

\section{Cells and culture conditions}

Human CAFs were isolated from fresh surgical specimens of pancreatic cancer using the outgrowth method [8]. Primary cultures of CAFs derived from 22 patients with invasive pancreatic cancer were established in our laboratory. The cell type was confirmed by a spindle-shaped morphology and immunofluorescence staining for $\alpha$-SMA and vimentin $[13,48]$. Passage $3-8$ cells were used for assays. In addition, the following 10 pancreatic cancer cell lines were used: PANC-1, SUIT-2, KP-2, and AsPC-1 (Dr. Iguchi, National Shikoku Cancer Center, Matsuyama, Japan); MIAPaCa-2 (Japanese Cancer Resource Bank, Tokyo, Japan); BxPC-3, Capan-2, CFPAC-1, and SW 1990 (American Type Culture Collection, Manassas, VA); and HPC-3 (Dr. Yasoshima, Sapporo Medical University, Hokkaido, Japan). The lung squamous cancer cell line H157 (Dr. Onimaru, Kyushu University, Fukuoka, Japan) was used as a positive control for PDPN expression [20]. Cells were maintained as described previously $[20,49]$. In the PDPN induction assay, DMEM (Sigma Chemical Co., St. Louis, MO) or DMEM containing no glucose (Invitrogen, Carlsbad, CA) was used for cell culture. Media were supplemented with $2 \%$ or $10 \%$ fetal bovine serum (FBS) (Invitrogen), $10 \mathrm{ng} / \mathrm{ml}$ TGF- $\beta 1$ (R\&D, Oxon, UK), $50 \mathrm{ng} / \mathrm{ml} \mathrm{FGF-2} \mathrm{(Sigma,} \mathrm{Basel,} \mathrm{Switzerland),} 100 \mathrm{ng} / \mathrm{ml}$ IGF-1 (R\&D), and $100 \mathrm{ng} / \mathrm{ml}$ EGF (Sigma).

\section{Immunohistochemical procedures and evaluation}

Immunohistochemical staining was conducted as described previously [29]. Formalin-fixed, paraffin-embedded tissue was cut at 4- $\mu \mathrm{m}$ thicknesses and deparaffinized with xylene and ethanol. The endogenous peroxidase activity was blocked by methanol containing $0.3 \%$ hydrogen peroxidase. Antigen retrieval was performed by boiling in a microwave oven (citrate buffer, $\mathrm{pH}$ 6.0). The sections were incubated overnight at $4{ }^{\circ} \mathrm{C}$ with primary antibodies against PDPN (413541; mouse monoclonal, D2-40; Nichirei Bioscience, Tokyo, Japan) and $\alpha$-SMA (A2547; mouse monoclonal, 1:400; Sigma, St Louis, MO). The immune complexs were then visualized using EnVision Detection System (Dako, Glostrup, Denmark) and 3,3'-diaminobenzidine (DAB) Kit (Dako). We performed immunohistochemical staining for PDPN and $\alpha$-SMA in consecutive sections, and fibroblastlike cells involved with the cancer cells or cancer ducts were $\alpha$-SMA positive, as shown in a previous report [46]. We confirmed the cell type by a spindle-shaped morphology and $\alpha$-SMA positivity. PDPN was also expressed by such fibroblast-like cells, and we assumed those cells to be CAFs. All sections were evaluated independently by two investigators without any knowledge of the clinical features. Stromal expression of PDPN was defined as positive when over than $30 \%$ of the stromal fibroblasts around neoplastic cells were stained. The stromal cells around normal pancreatic ducts were also evaluated in 20 cases of normal pancreatic tissue. PDPN expression was not observed in any carcinoma cells. Lymphatic vessels stained positive for PDPN without exception, and were used as a positive control.

\section{Immunocytochemical staining of CAFs}

Immunocytochemical staining of CAFs was conducted using a streptavidin-biotin-peroxidase complex method (Histofine; Nichirei, Tokyo, Japan), with primary antibodies against PDPN (413541; mouse monoclonal, D240, Nichirei Bioscience). Cultured cells were fixed on culture slides for $20 \mathrm{~min}$ in methanol/acetone at $4^{\circ} \mathrm{C}$. Endogenous peroxidase activity was blocked by treatment with methanol containing $0.3 \%$ hydrogen peroxidase for $20 \mathrm{~min}$. Antigen retrieval was conducted by microwave heating for $20 \mathrm{~min}$ with sodium citrate buffer (pH 6.0). After exposure to $10 \%$ non-immunized goat serum in PBS for $20 \mathrm{~min}$, sections were incubated with primary antibody at room temperature for $90 \mathrm{~min}$. Subsequent reactions were performed according to the peroxidase-labeled streptavidin-biotin technique using a histofine SAB-PO kit (Nichirei). The reaction products were visualized using diaminobenzidine tetrahydrochloride as a chromogen. Finally, the sections were counterstained with hematoxylin. Harvested CAFs were treated with trypsin/EDTA for $5 \mathrm{~min}$, then centrifuged at $1,600 \times g$. for $5 \mathrm{~min}$ and fixed for $3 \mathrm{~h}$ by mixing with $5 \mathrm{~mL} \mathrm{10 \%} \mathrm{formalin.} \mathrm{Cells} \mathrm{were} \mathrm{centrifuged} \mathrm{for} 5 \mathrm{~min}$ and the supernatant was removed, followed by the addition of $0.5 \mathrm{ml} 1 \%$ sodium alginate. After centrifugation for a further $5 \mathrm{~min}, 2$ drops of $1 \mathrm{M}$ calcium chloride solution were added. The concretions were embedded in paraffin. Sections were cut at $4 \mu \mathrm{m}$ and stained with PDPN.

\section{Real-time qRT-PCR}

One-step real-time qRT-PCR with gene-specific priming was performed as described previously [13]. The total RNA was extracted from cultured cells using a High Pure RNA Isolation Kit (Roche Diagnostics, Mannheim, Germany) and DNase I (Roche Diagnostics) treatment according to the manufacturer's instructions. One-step real-time qRTPCR was performed using a QuantiTect SYBR Green Reverse Transcription-PCR Kit (Qiagen, Tokyo, Japan) and a CFX96 Touch Real-Time PCR Detection System (Bio-Rad Laboratories, Hercules, CA). Primers for PDPN, CD10, MMP2, MMP3, glyceraldehyde-3-phosphate dehydrogenase (GAPDH), and $18 \mathrm{~S}$ ribosomal RNA (18SrRNA) were purchased from Takara Bio Inc. (Tokyo, Japan). The primer sequences are listed in Additional file 5: 
Table S2. Each reaction mixture was first incubated at $50^{\circ} \mathrm{C}$ for 30 minutes to allow reverse transcription in which firststrand complementary DNA was synthesized by priming total RNA with a gene-specific primer. PCR was initiated by incubation at $95^{\circ} \mathrm{C}$ for 15 minutes to activate the polymerase, followed by 40 cycles of $95^{\circ} \mathrm{C}$ for 5 seconds, $60^{\circ} \mathrm{C}$ for 20 seconds, and $72^{\circ} \mathrm{C}$ for 30 seconds. The gene expression levels were calculated using a standard curve constructed with total RNA from H157 (a lung squamous cell line), SUIT-2 (a pancreatic cancer cell line), or specific CAFs. The levels of gene expression were normalized to those of GAPDH or 18SrRNA as an internal control and calculated as the ratio of target gene expression to GAPDH or 18SrRNA expression. The quantitative ranges of threshold cycles observed were 15-35 cycles for each of the target genes and 5-25 cycles for GAPDH and 18SrRNA. All samples were run in triplicate, and each sample was analyzed three times. No detectable PCR products were amplified without prior reverse transcription. The accuracy and integrity of the PCR products were confirmed using an Agilent 2100 Bioanalyzer (Agilent Technologies Inc., Palo Alto, CA).

\section{Immunofluorescence staining}

CAFs were plated on glass-bottom dishes (Matsunami, Osaka, Japan) and incubated for 24 hours in DMEM supplemented with $10 \%$ FBS. The cells were then fixed with methanol, blocked with 3\% bovine serum albumin in PBS, and incubated with mouse monoclonal anti- $\alpha$-SMA (N1584; 1:50; Dako) or rabbit polyclonal anti-PDPN (sc-134482; 1:50; Santa Cruz Biotechnology, Santa Cruz, $\mathrm{CA}$ ) antibodies overnight at $4^{\circ} \mathrm{C}$. The cells were then incubated with Alexa Fluor 546-conjugated anti-mouse IgG and Alexa Fluor 488-conjugated anti-rabbit IgG (Molecular Probes, Eugene, OR) for 1 hour. Nuclei were counterstained with 4',6-diamidino-2-phenylindole $(0.05 \mathrm{mg} / \mathrm{ml})$. Labeled cells were observed under a fluorescence microscope (BZ-9000E; Keyence, Osaka, Japan), and images were obtained using a BZ-II analyzer (Keyence, Osaka, Japan).

\section{Flow cytometric analysis}

Subconfluent cells were harvested by exposure to trypsin/EDTA for 5 minutes at $37^{\circ} \mathrm{C}$, and then washed in DMEM/10\% FBS. The cells were resuspended in $1 \%$ FBS/PBS at $1 \times 10^{6}$ cells/95 $\mu \mathrm{l}$ and incubated with $5 \mu \mathrm{l}$ phycoerythrin (PE)-conjugated anti-PDPN antibody (129381; eBioscience Inc., San Diego, CA) on ice for $30 \mathrm{mi}-$ nutes. We also stained cells with nonspecific rat IgG2 Control PE (12-4321; eBioscience Inc.) for the negative control. To detect FAP positive cells, the cells were resuspended in $1 \% \mathrm{FBS} / \mathrm{PBS}$ at $1 \times 10^{6}$ cells/95 $\mu \mathrm{l}$ and incubated with $5 \mu \mathrm{l}(2.5 \mu \mathrm{g})$ anti-human FAP mouse monoclonal antibody (MAB3715; R\&D) on ice for $30 \mathrm{mi}-$ nutes. After washing twice, the cells in $99 \mu \mathrm{l}$ of $1 \%$ FBS/
PBS were incubated with $1 \mu \mathrm{l}$ of allophycocyanin (APC) anti-mouse IgG antibodies (Sony Corporation, Tokyo, Japan) on ice for 30 minutes. Labeled cells were analyzed using a flow cytometer (EC800; Sony) equipped with a laser that provided an excitation wavelength of $488 \mathrm{~nm}$ for PE and $642 \mathrm{~nm}$ for APC. Data were analyzed using Eclipse Analysis software (Sony).

\section{Isolation of CAFs by immunoreactivity for PDPN}

After labeling the cells with PE-conjugated anti-PDPN antibody, we added magnetic microbeads conjugated with an anti-PE reagent, followed by incubation for 15 minutes at $4^{\circ} \mathrm{C}$. PDPN+ cells were isolated by passing the suspension through an AutoMACS PRO separator (Miltenyi Biotechnology). The purity of isolated populations was about $95 \%$. Unlabeled cells were negatively selected and collected by the depletion method through the AutoMACS PRO separator. Unlabeled cells were almost 0\% PDPN+.

\section{Indirect co-culture system}

Indirect co-culture was performed using a 6-well transwell culture system with $3-\mu \mathrm{m}$ cell culture inserts (Becton Dickinson Labware, Franklin Lakes, NJ) as described previously [38]. CAFs were co-cultured with pancreatic cancer cells. Two types of CAFs $\left(5 \times 10^{4}\right.$ cells $)$ were seeded in the lower chambers. After 24 hours of culture, $5 \times 10^{4}$ cells from cancer cell lines were seeded in the upper chambers with DMEM supplemented with 2\% FBS. After incubation for 72 and 120 hours, we examined the percentage of PDPN + CAFs by flow cytometry. For the control, the percentage of PDPN + CAFs in monoculture was examined.

\section{Migration and matrigel invasion assays}

Migration and invasion of cultured cancer cells were assessed by counting the number of cells migrating or invading through uncoated or Matrigel-coated transwell chambers (BD Biosciences, Franklin Lakes, NJ) as described previously $[49,50]$. We used transwell inserts with $8-\mu \mathrm{m}$ pores. Uncoated transwell chambers were used for the migration assay, and chambers coated with $20 \mu \mathrm{g} /$ well Matrigel (BD Biosciences, Bedford, MA) were used for the invasion assay. Cancer cells $\left(5 \times 10^{4}\right.$ cells/ $\mathrm{ml}, 0.25 \mathrm{ml}$ medium) were seeded in the upper chambers. For co-cultures, $5 \times 10^{4} \mathrm{CAFs} / 0.75 \mathrm{ml}$ medium were seeded in the lower chambers at 24 hours before cancer cell seeding. The cells were then incubated for 18 hours (PANC-1) and 24 hours (SUIT-2) for the migration assay, and 24 hours (PANC-1) and 48 hours (SUIT-2) for the invasion assay. Cancer cells at the lower surface of the membrane were fixed with $70 \%$ ethanol, stained with hematoxylin and eosin, and counted in five random fields at $\times 200$ magnification under a microscope. 
Each experiment was carried out in triplicate wells, and independent experiments were repeated at least three times.

\section{Silencing of PDPN by siRNA}

We performed knockdown of PDPN by siRNA according to the manufacturer's instructions. CAFs $\left(1 \times 10^{5}\right.$ cells $)$ were transfected with PDPN-1 siRNA (sil) and T1A-2 siRNA (si2) siRNA (Qiagen)/Lipofectamine RNAiMax transfection reagent (Invitrogen)/Opti-MEM (Invitrogen) complexes for the indicated time. After transfection, the cells were cultured in fresh DMEM containing 10\% FBS at $37^{\circ} \mathrm{C}$. The effect of siRNA was confirmed by qRT-PCR and western blotting. To verify the specificity of knockdown, we used negative control siRNA (Qiagen). CAFs were used in subsequent experiments at 72 hours after transfection.

\section{Western blotting analysis}

Protein was extracted from CAFs using PRO-PREP (iNtRON biotechnology, Seongnam, Korea) according to the manufacturer's instructions. From each sample, $20 \mu \mathrm{g}$ of protein was run on a $4 \%$ to $12 \%$ gradient Bis-Tris- $\mathrm{HCl}$ buffered (pH 6.4) polyacrylamide gel (NuPAGE Novex 412\% Bis-Tris Gel, Invitrogen, Life Technologies, Carlsbad, $\mathrm{CA}$ ) and transferred to a polyvinylidene difluoride membrane (Millipore, Billerica, MA). The membrane was incubated overnight at $4^{\circ} \mathrm{C}$ with anti-PDPN (11-003; 1:200; AngioBio Co., Del Mar, CA), anti-CD10 (NCL-CD10-270; 1:100; Novocastra, Newcastle Upon Tyne, UK), or anti- $\alpha$ tubulin (05-829; 1:1000; Millipore, Billerica, MA) antibodies and then probed with secondary antibodies conjugated to horseradish peroxidase (Santa Cruz Biotechnology). Immunoblots were detected by enhanced chemiluminescence with ChemiDoc XRS (Bio-Rad Laboratories).

\section{Statistical analysis}

Values were expressed as the mean \pm standard deviation. Comparisons between two groups were made using the Student's $t$-test. All experiments were repeated three times. Statistical significance was defined as $P<0.05$. The $\chi^{2}$ test was used to analyze correlations between immunohistochemical staining of PDPN and clinicopathologic characteristics. Survival curves were constructed using the Kaplan-Meier method and compared using the log-rank test. To evaluate independent prognostic factors associated with survival, a multivariate Cox proportional-hazards regression analysis was used. All statistical analyses were performed using JMP 8.0 software (SAS Institute, Cary, NC).

\section{Additional files}

Additional file 1: Figure S1. Flow cytometric analysis and immunocytochemical staining of CAFs to characterize. (A) The rate of PDPN expression in CAFs did not differ according to the length of
trypsin/EDTA treatment after 2, 5, and 10 minutes. (B)

Immunocytochemical staining of PDPN for cultured CAFs (upper) and harvested CAFs after trypsin/EDTA treatment for 5 min (lower). Original magnification $\times 400$. (C) All the primary cultured CAFs (CAF1, CAF2, CAF3, and CAF4) were positive for FAP in most cells.

Additional file 2: Figure S2. CAFs (CAF3 and CAF4) were sorted into two populations based on their expression of PDPN to investigate the biological functions of PDPN+ CAFs. (A) Analysis of the PDPN+ population among parental CAF4 cells (left) and reanalysis of the sorted PDPN+ cells (right upper, 90.8\% PDPN+ cells) and PDPN- cells (right lower, $0.44 \%$ PDPN+ cells). (B) qRT-PCR was performed to measure the PDPN mRNA expression in CAF1 cells, CAF2 cells, and sorted PDPN+ and PDPN- CAFs.

Additional file 3: Figure S3. PDPN knockdown in CAF1 cells by siRNA. Transfection of PDPN-1 siRNA (si1) and T1A-2 siRNA (si2) decreased PDPN mRNA expression $(\mathbf{A})$ resulting in decreased levels of PDPN protein in cells as shown by western blotting at the indicated times (B). Knockdown of PDPN in CAF1 cells by siRNA showed no differences in the migration (C) or invasion (D) of PANC-1 and SUIT-2 cells compared with the control cells (n.s.: not significant).

Additional file 4: Table S1. Clinicopathological characteristics of the 105 patients with pancreatic IDC.

Additional file 5: Table S2. Primers used for $\mathrm{QRT} T-P C R$.

Competing interests

The authors declare that they have no competing interests.

\section{Authors' contributions}

YO formulated the study design. KS and SA designed the experiments, carried out the study, and prepared the manuscript. KO supervised the statistical analysis and revised the manuscript. KF provided clinical data including prognostic markers and survival. MF, YM, and MH performed the histopathological assessments of the patients. KM and MT supervised the interpretations of results, and revised the manuscript. All authors read and approved the final manuscript.

\section{Acknowledgments}

We thank N. Tateishi (Department of Anatomic Pathology, Kyushu University Hospital) and E. Manabe (Department of Surgery and Oncology, Kyushu University Hospital) for their expert technical assistance. We also thank Edanz Group Japan for English language editing.

\section{Financial support}

This work was supported in part by a Grant-in-Aid for Japan Society for the Promotion of Science (JSPS) fellows.

\section{Author details}

'Department of Anatomic Pathology, Graduate School of Medical Sciences, Kyushu University, 3-1-1 Maidashi, Fukuoka 812-8582, Japan. Department of Surgery and Oncology, Graduate School of Medical Sciences, Kyushu University, 3-1-1 Maidashi, Fukuoka 812-8582, Japan. ${ }^{3}$ Advanced Medical Initiatives, Graduate School of Medical Sciences, Kyushu University, 3-1-1 Maidashi, Fukuoka 812-8582, Japan. ${ }^{4}$ Kyushu University Hospital Cancer Center, Fukuoka 812-8582, Japan. ${ }^{5}$ Research Fellow of Japan Society for the Promotion of Science, Tokyo, Japan.

Received: 16 July 2013 Accepted: 16 December 2013 Published: 20 December 2013

\section{References}

1. Siegel R, Naishadham D, Jemal A: Cancer statistics, 2013. CA Cancer J Clin 2013, 63:11-30

2. Cleary SP, Gryfe R, Guindi M, Greig P, Smith L, Mackenzie R, Strasberg S, Hanna S, Taylor B, Langer B, Gallinger S: Prognostic factors in resected pancreatic adenocarcinoma: analysis of actual 5-year survivors. J Am Coll Surg 2004, 198:722-731.

3. Hwang RF, Moore T, Arumugam T, Ramachandran V, Amos KD, Rivera A, Ji $B$, Evans DB, Logsdon CD: Cancer-associated stromal fibroblasts promote pancreatic tumor progression. Cancer Res 2008, 68:918-926. 
4. Kalluri R, Zeisberg M: Fibroblasts in cancer. Nat Rev Canc 2006, 6:392-401.

5. Couvelard A, O'Toole D, Leek R, Turley H, Sauvanet A, Degott C, Ruszniewski $P$, Belghiti J, Harris AL, Gatter K, Pezzella F: Expression of hypoxia-inducible factors is correlated with the presence of a fibrotic focus and angiogenesis in pancreatic ductal adenocarcinomas. Histopathology 2005, 46:668-676.

6. Neesse A, Michl P, Frese KK, Feig C, Cook N, Jacobetz MA, Lolkema MP, Buchholz M, Olive KP, Gress TM, Tuveson DA: Stromal biology and therapy in pancreatic cancer. Gut 2011, 60:861-868.

7. Apte MV, Haber PS, Applegate TL, Norton ID, McCaughan GW, Korsten MA Pirola RC, Wilson JS: Periacinar stellate shaped cells in rat pancreas: identification, isolation, and culture. Gut 1998, 43:128-133.

8. Bachem MG, Schneider E, Gross H, Weidenbach H, Schmid RM, Menke A, Siech M, Beger H, Grunert A, Adler G: Identification, culture, and characterization of pancreatic stellate cells in rats and humans. Gastroenterology 1998, 115:421-432.

9. Erkan M, Adler G, Apte MV, Bachem MG, Buchholz M, Detlefsen S, Esposito I, Friess H, Gress TM, Habisch HJ, Hwang RF, Jaster R, Kleeff J, Kloppel G, Kordes C, Logsdon CD, Masamune A, Michalski CW, Oh J, Phillips PA, Pinzani M, Reiser-Erkan C, Tsukamoto H, Wilson J: StellaTUM: current consensus and discussion on pancreatic stellate cell research. Gut 2012, 61:172-178.

10. Masamune A, Watanabe T, Kikuta K, Shimosegawa T: Roles of pancreatic stellate cells in pancreatic inflammation and fibrosis. Clin Gastroenterol Hepatol 2009, 7:S48-54.

11. Habisch H, Zhou S, Siech M, Bachem MG: Interaction of stellate cells with pancreatic carcinoma cells. Cancers 2010, 2:1661-1682.

12. Froeling FE, Feig C, Chelala C, Dobson R, Mein CE, Tuveson DA, Clevers H, Hart IR, Kocher HM: Retinoic acid-induced pancreatic stellate cell quiescence reduces paracrine Wnt-beta-catenin signaling to slow tumor progression. Gastroenterology 2011, 141:1486-1497. 1497 e1481-1414.

13. Ikenaga N, Ohuchida K, Mizumoto K, Cui L, Kayashima T, Morimatsu K, Moriyama T, Nakata K, Fujita H, Tanaka M: CD10+ pancreatic stellate cells enhance the progression of pancreatic cancer. Gastroenterology 2010, 139:1041-1051. 1051 e1041-1048.

14. Breiteneder-Geleff S, Soleiman A, Kowalski H, Horvat R, Amann G, Kriehuber E, Diem K, Weninger W, Tschachler E, Alitalo K, Kerjaschki D: Angiosarcomas express mixed endothelial phenotypes of blood and lymphatic capillaries: podoplanin as a specific marker for lymphatic endothelium. Am J Pathol 1999, 154:385-394.

15. Matsui K, Breitender-Geleff S, Soleiman A, Kowalski H, Kerjaschki D: Podoplanin, a novel 43-kDa membrane protein, controls the shape of podocytes. Nephrol Dial Transplant 1999, 14(Suppl 1):9-11.

16. Rishi AK, Joyce-Brady M, Fisher J, Dobbs LG, Floros J, VanderSpek J, Brody JS, Williams MC: Cloning, characterization, and development expression of a rat lung alveolar type I cell gene in embryonic endodermal and neural derivatives. Dev Biol 1995, 167:294-306.

17. Schacht V, Dadras SS, Johnson LA, Jackson DG, Hong YK, Detmar M: Up-regulation of the lymphatic marker podoplanin, a mucin-type transmembrane glycoprotein, in human squamous cell carcinomas and germ cell tumors. Am J Pathol 2005, 166:913-921.

18. Ordonez NG: The diagnostic utility of immunohistochemistry and electron microscopy in distinguishing between peritoneal mesotheliomas and serous carcinomas: a comparative study. Mod Pathol 2006, 19:34-48.

19. Wicki A, Christofori G: The potential role of podoplanin in tumour invasion. Br J Cancer 2007, 96:1-5.

20. Suzuki $H$, Onimaru $M$, Yonemitsu $Y$, Maehara $Y$, Nakamura S, Sueishi K: Podoplanin in cancer cells is experimentally able to attenuate prolymphangiogenic and lymphogenous metastatic potentials of lung squamoid cancer cells. Mol Cancer 2010, 9:287.

21. Yuan P, Temam S, El-Naggar A, Zhou X, Liu DD, Lee JJ, Mao L: Overexpression of podoplanin in oral cancer and its association with poor clinical outcome. Cancer 2006, 107:563-569.

22. Xu Y, Ogose A, Kawashima H, Hotta T, Ariizumi T, Li G, Umezu H, Endo N: High-level expression of podoplanin in benign and malignant soft tissue tumors: immunohistochemical and quantitative real-time RT-PCR analysis. Oncol Rep 2011, 25:599-607.

23. Chandramohan V, Bao X, Kato Kaneko M, Kato Y, Keir ST, Szafranski SE, Kuan $\mathrm{CT}$, Pastan $\mathrm{H}$, Bigner DD: Recombinant anti-podoplanin (NZ-1) immunotoxin for the treatment of malignant brain tumors. Int J Canc Suppl J Int Canc Suppl 2013, 132:2339-2348.
24. Kaneko MK, Kato Y, Kitano T, Osawa M: Conservation of a platelet activating domain of Aggrus/podoplanin as a platelet aggregationinducing factor. Gene 2006, 378:52-57.

25. Kunita A, Kashima TG, Ohazama A, Grigoriadis AE, Fukayama M: Podoplanin is regulated by AP-1 and promotes platelet aggregation and cell migration in osteosarcoma. Am J Pathol 2011, 179:1041-1049.

26. Scholl FG, Gamallo C, Vilaro S, Quintanilla M: Identification of PA2.26 antigen as a novel cell-surface mucin-type glycoprotein that induces plasma membrane extensions and increased motility in keratinocytes. J Cell Sci 1999, 112(Pt 24):4601-4613.

27. Wicki A, Lehembre F, Wick N, Hantusch B, Kerjaschki D, Christofori G: Tumor invasion in the absence of epithelial-mesenchymal transition: podoplanin-mediated remodeling of the actin cytoskeleton. Cancer cell 2006, 9:261-272

28. Martin-Villar E, Megias D, Castel S, Yurrita MM, Vilaro S, Quintanilla M: Podoplanin binds ERM proteins to activate RhoA and promote epithelial-mesenchymal transition. J Cell Sci 2006, 119:4541-4553.

29. Aishima S, Nishihara Y, Iguchi T, Taguchi K, Taketomi A, Maehara Y, Tsuneyoshi M: Lymphatic spread is related to VEGF-C expression and D240-positive myofibroblasts in intrahepatic cholangiocarcinoma. Mod Pathol 2008, 21:256-264.

30. Carvalho FM, Zaganelli FL, Almeida BGL, Goes JCS, Baracat EC, Carvalho JP: Prognostic value of podoplanin expression in intratumoral stroma and neoplastic cells of uterine cervical carcinomas. Clinics 2010, 65:1279-1283.

31. Hoshino A, Ishii G, Ito T, Aoyagi K, Ohtaki Y, Nagai K, Sasaki H, Ochiai A Podoplanin-positive fibroblasts enhance lung adenocarcinoma tumor formation: podoplanin in fibroblast functions for tumor progression. Cancer Res 2011, 71:4769-4779.

32. Kawase A, Ishii G, Nagai K, Ito T, Nagano T, Murata $Y$, Hishida T, Nishimura M, Yoshida J, Suzuki K, Ochiai A: Podoplanin expression by cancer associated fibroblasts predicts poor prognosis of lung adenocarcinoma. Int J Cancer 2008, 123:1053-1059.

33. Kitano H, Kageyama S, Hewitt SM, Hayashi R, Doki Y, Ozaki Y, Fujino S, Takikita M, Kubo H, Fukuoka J: Podoplanin expression in cancerous stroma induces lymphangiogenesis and predicts lymphatic spread and patient survival. Arch Pathol Lab Med 2010, 134:1520-1527.

34. Pula B, Jethon A, Piotrowska A, Gomulkiewicz A, Owczarek T, Calik J, Wojnar A, Witkiewicz W, Rys J, Ugorski M, Dziegiel P, Podhorska-Okolow M: Podoplanin expression by cancer-associated fibroblasts predicts poor outcome in invasive ductal breast carcinoma. Histopathology 2011, 59:1249-1260.

35. Yamanashi T, Nakanishi Y, Fujii G, Akishima-Fukasawa Y, Moriya Y, Kanai Y, Watanabe M, Hirohashi S: Podoplanin expression identified in stromal fibroblasts as a favorable prognostic marker in patients with colorectal carcinoma. Oncology 2009, 77:53-62.

36. Zhang Y, Tang H, Cai J, Zhang T, Guo J, Feng D, Wang Z: Ovarian cancer-associated fibroblasts contribute to epithelial ovarian carcinoma metastasis by promoting angiogenesis, lymphangiogenesis and tumor cell invasion. Cancer Lett 2011, 303:47-55.

37. Edge SB, Byrd DR, Compton CC, Fritz AG, Greene FL, Trotti A (Eds): Exocrine and Endocrine Pancreas, AJCC cancer staging manual. 7th edition. New York: Springer; 2010:241-248.

38. Fujita H, Ohuchida K, Mizumoto K, Egami T, Miyoshi K, Moriyama T, Cui L, Yu J, Zhao M, Manabe T, Tanaka M: Tumor-stromal interactions with direct cell contacts enhance proliferation of human pancreatic carcinoma cells. Cancer Sci 2009, 100:2309-2317.

39. Egeblad $M$, Werb Z: New functions for the matrix metalloproteinases in cancer progression. Nat Rev Canc 2002, 2:161-174.

40. Seiki M: The cell surface: the stage for matrix metalloproteinase regulation of migration. Curr Opin Cell Biol 2002, 14:624-632.

41. Cirri P, Chiarugi P: Cancer associated fibroblasts: the dark side of the coin. American journal of cancer research 2011, 1:482-497.

42. Madar S, Goldstein I, Rotter V: 'Cancer associated fibroblasts'-more than meets the eye. Trends Mol Med 2013, 19:447-453.

43. Erez N, Truitt M, Olson P, Arron ST, Hanahan D: Cancer-associated fibroblasts are activated in incipient neoplasia to orchestrate tumor-promoting inflammation in an NF-kappaB-dependent manner. Cancer Cell 2010, 17:135-147.

44. Lee HO, Mullins SR, Franco-Barraza J, Valianou M, Cukierman E, Cheng JD: FAP-overexpressing fibroblasts produce an extracellular matrix that 
enhances invasive velocity and directionality of pancreatic cancer cells. BMC Cancer 2011, 11:245.

45. Roberts EW, Deonarine A, Jones JO, Denton AE, Feig C, Lyons SK, Espeli M, Kraman M, McKenna B, Wells RJ, Zhao Q, Caballero OL, Larder R, Coll AP, O'Rahilly S, Brindle KM, Teichmann SA, Tuveson DA, Fearon DT: Depletion of stromal cells expressing fibroblast activation protein-alpha from skeletal muscle and bone marrow results in cachexia and anemia. J Exp Med 2013, 210:1137-1151.

46. Fujita H, Ohuchida K, Mizumoto K, Nakata K, Yu J, Kayashima T, Cui L, Manabe T, Ohtsuka T, Tanaka M: Alpha-smooth muscle actin expressing stroma promotes an aggressive tumor biology in pancreatic ductal adenocarcinoma. Pancreas 2010, 39:1254-1262.

47. Hruban RH, Klöppel G, Boffetta P, Maitra A, Hiraoka N, Offerhaus GJA, Lacobuzio-Donahue C, Pitman MB, Kato Y, Kern SE, Klimstra DS: Ductal adenocarcinoma of the pancreas. In WHO classification of tumours of the digestive system. World Health Organization; 2010:281-291.

48. Eguchi D, Ikenaga N, Ohuchida K, Kozono S, Cui L, Fujiwara K, Fujino M, Ohtsuka T, Mizumoto K, Tanaka M: Hypoxia enhances the interaction between pancreatic stellate cells and cancer cells via increased secretion of connective tissue growth factor. J Surg Res 2013, 181:225-233.

49. Ohuchida K, Mizumoto K, Murakami M, Qian LW, Sato N, Nagai E, Matsumoto K, Nakamura T, Tanaka M: Radiation to stromal fibroblasts increases invasiveness of pancreatic cancer cells through tumor-stromal interactions. Cancer Res 2004, 64:3215-3222.

50. Iwamoto Y, Tanaka K, Okuyama K, Sugioka Y, Taniguchi S: In vitro assay of the invasive potential of malignant bone and soft tissue tumours through basement membranes. Int Orthop 1994, 18:240-247.

doi:10.1186/1476-4598-12-168

Cite this article as: Shindo et al: Podoplanin expression in cancerassociated fibroblasts enhances tumor progression of invasive ductal carcinoma of the pancreas. Molecular Cancer 2013 12:168.

\section{Submit your next manuscript to BioMed Central and take full advantage of:}

- Convenient online submission

- Thorough peer review

- No space constraints or color figure charges

- Immediate publication on acceptance

- Inclusion in PubMed, CAS, Scopus and Google Scholar

- Research which is freely available for redistribution 